\title{
Aplikasi Panduan Sholat Wajib dan Sholat Sunnah Berbasis Android
}

\author{
Petricia Oktavia $^{1}$, Muhamad Meky Frindo ${ }^{2}$ \\ Teknik Informatika, Universitas Pamulang, Jl. Raya Puspitek No.46, Buaran, Serpong, Tangerang \\ Selatan, Banten, Indonesia, 15310 \\ e-mail: ${ }^{1}$ dosen00638@unpam.ac.id, ${ }^{2}$ dosen00678@unpam.ac.id \\ Submitted Date: April 22 $2^{\text {nd }}, 2020$ \\ Revised Date: June $30^{\text {th }}, 2020$ \\ Reviewed Date: May $11^{\text {th }}, 2020$ \\ Accepted Date: June $30^{\text {th }}, 2020$
}

\begin{abstract}
Technology has always been and will continue to develop, especially mobile based applications. Gadgets or devices become a media that becomes the choice to carry out useful processes such as education, in the era of all-round technology today or known as the millennial era. Not to be the main to students but to be fostered by the teacher, need guidance that will help from the beginning of the guide followed by a systematic evaluation process. Alpabeta Kindergarten is one of the kindergartens that have begun to implement prayer learning from an early age for students who are Muslim and have difficulty in implementation because the guidelines available in the form of books or applications are not accompanied by an evaluation process. The idea to design and build an Android-based application that can be an alternative solution in providing information on obligatory prayer and sunnah accompanied by a one-way evaluation process. This application serves as a media guide to obligatory and sunnah prayers and facilitate the community, especially students of Alpabeta Kindergarten for the learning process of obligatory prayers and sunnah prayers. The research method consists of 5 (five) stages including gathering needs, analyzing needs, designing applications, integrating and testing prototype forms, implementing prototype applications and evaluating. The results of testing the prototype application of the obligatory and sunnah prayer guides are as functional as expected. Evaluation of the application is also good with almost $99 \%$ presentation because all buttons on this application can run well and the application is easy to understand and easy to use by teachers and students of Kindergarten Alpabeta.
\end{abstract}

Keyword: Pray guide; Android; Waterfall Model; Evaluation.

\section{Abstrak}

Teknologi selalu dan akan terus berkembang, terutama aplikasi berbasis mobile. Gadget atau gawai menjadi satu media yang jadi pilihan untuk melakukan proses bermanfaat seperti pendidikan, di era serba teknologi saat ini atau dikenal dengan zaman milineal. Tidak menjadi utama ke siswa tapi dengan dibina oleh guru, membutuhkan panduan yang akan membantu dari awal panduan dengan diikuti proses evaluasi secara sistematik. TK Alpabeta merupakan satu dari sekian TK yang sudah mulai menerapkan pembelajaran sholat sejak usia dini bagi siswa-siswi yang beragama islam dan mengalami kesulitan dalam implementasi karena panduan yang tersedia dalam bentuk buku ataupun aplikasi tidak disertai dengan proses evaluasi. Gagasan untuk merancang bangun aplikasi berbasis android yang dapat menjadi salah satu alternatif solusi dalam memberikan informasi panduan sholat wajib dan sunnah disertai proses evaluasi satu arah. Aplikasi ini berfungsi sebagai media panduan sholat wajib dan sunnah serta mempermudah masyarakat khususnya murid TK Alpabeta untuk proses pembelajaran sholat wajib dan sholat sunnah. Metode penelitian terdiri dari 5 (lima) tahap yakni pengumpulan kebutuhan, analisis kebutuhan, desain aplikasi, integrasi dan pengujian bentuk prototipe, penerapan aplikasi prototipe dan evaluasi. Hasil pengujian aplikasi prototipe panduan shalat wajib dan sunnah ini telah sesuai dengan yang diharapkan secara fungsional. Evaluasi aplikasi juga baik dengan presentasi hampir 99\% dikarenakan semua button pada aplikasi ini dapat berjalan dengan baik dan aplikasi ini mudah dipahami dan mudah digunakan oleh guru dan murid TK Alpabeta.

Kata Kunci : Panduan Sholat; Android; Waterfall; Evaluasi 


\section{Pendahuluan}

Pendidikan merupakan usaha yang direncanakan dan disadari agar dapat mewujudkan proses belajar mengajar siswa dengan aktif mengembangkan semua potensi yang ada dalam diri siswa, sehingga dapat membentuk spiritual agama, mengendalikan diri, berkepribadian, cerdas, berakhlak mulia, dan terampil yang nantinya berguna bagi dirinya, masyarakat banyak, bangsa juga negara, hal ini ada pada undang undang nomor 20 tahun 2003 yang membahas sistem pendidikan nasional. Ibadah sholat merupakan satu media komunikasi antara manusia (umat islam) dengan Allah Subhanahu Wa Ta'ala, dan ada cara maupun media lainnya. Rukun islam kedua ini menjadi amaliah ibadah seseorang hambaNya kepada Khaliknya, suatu cara agar menjadi dekat diri atas hikmah dari gerakan yang ada dan dilakukan di dalam ibadah sholat, baik itu sholat wajib ataupun sholat sunnah. Di agama islam, ibadah sholat merupakan ibadah dengan kedudukan tertinggi jika kita bandingkan dengan ibadah yang ada lainnya, sholat juga merupakan ikatan islam yang lepas paling akhir (Rahmatullah, 2016). Pendidikan agama islam dengan mempelajari ibadah tertinggi agar siswa mampu membentuk spiritual agama dengan benar dan baik.

Sholat fardhu lima waktu merupakan sebuah tiang atau pondasi utama menopang sebuah bangunan. Maka apabila tiangnya rapuh ataupun tidak kuat, maka akan menjadi roboh bangunan yang menjadi sanggahnya. Rasulullah Shallallahu 'Alaihi wa Sallam bersabda yang menyatakan bahwa sholat sebagai pondasi agama islam, dan kita sebagai umatnya dilarang merobohkan pondasi ini (HR. Baihaqi). Membiasakan Pendidikan ibadah shalat ke anak usia dini sebaiknya memang dilakukan, peran orang tua, wali, dan guru sangat dibutuhkan sehingga akan siap shalat pada usia 7 (tujuh) tahun dan apabila usia 10 (sepuluh) tahun tidak melaksanakan shalat maka dibolehkan untuk berbuat tegas kepada anak (Amrulloh,A., 2016).

Pendidikan mengenai sholat pada TK Alpabeta sudah mulai diterapkan pada usia dini bagi murid nya yang beragam islam. TK Alpabeta memiliki jenjang Pendidikan mulai dari daycare untuk bayi hingga balita, Taman kana-kanan (TK) untuk balita persiapan untuk masuk sekolah dan Pendidikan usia Dini (paud) untuk mengajarkan ilmu agama islam seperti mengaji, akhlak dan lainlain. Pendidikan yang disampikan oleh guru kepada anak-anak usia dini perlu dengan cara yang menarik dan kreatif sehingga anak-anak murid mampu menerima dan mengerti. Rerata guru masih memakai buku teks untuk panduan saat memaparkan ringkasan. Akibatnya membuat anakanak, murid, siswa zaman milineal merasakan jenuh ataupun bosan dengan materi yang disampaikan oleh guru. Media pembelajaran dibutuhkan untuk mempermudah siswa belajar dengan optimal dan sebagai interaksi pendidik dengan anak didik sehingga mencapai tujuan belajar (Marjuni \& Harun, 2019).

Pola pendidikan sekarang perlu berbeda dengan pendidikan jaman dahulu, karena pengembangan luasnya media informasi yang akan mendukung terciptanya SCL (Student Centered Learning). Kurikulum perlu diterapkan dengan prinsip selangkah lebih maju. Sehingga proses belajar dengan basis teknologi menjadi satu alternatif untuk kegiatan belajar mengajar.

Kini, diiringi perkembangan zaman, hampir semua orang berlomba-lomba menghasilkan ide untuk dapat menciptakan hal yang baru yang akan dapat mempermudah pekerjaanya. Termasuk solusi dari perkembangan IT (Information and Technology) yang berkembang sangat pesat di dunia.

Beberapa penelitian sebelumnya yang menjadi referensi untuk dibuatnya sebuah aplikasi panduan sholat wajib dan sholat sunnah ini yaitu penelitian yang membangun aplikasi yang berisi jadwal dan pengingat waktu shalat sesuai lokasi pengguna, arah kiblat tepat lokasi dengan memanfaatkan Global Positioning System (GPS) sensor kompas juga memperhitungkan pergerakan magnetic north serta dilengkapi doa sehari-hari (Maharizki et al., 2016). Selanjutnya penelitian yang membahas tentang bagaimana perancangan aplikasi pembelajaran sholat lima waktu untuk anak-anak menggunakan metode Multimedia Development Life Cycle (MDLC) sehingga dilengkapi animasi tentang gerakan tata cara shalat, memiliki audio, informasi sholat lima waktu dan kompas digital (Lesmana et al., 2016). Kemudian penelitian pengembangan dari aplikasi yang sudah ada dengan menambahkan fitur tata cara tayamum, surat pendek AL-Quran dan doa sehari-hari dari aplikasi sebelumnya yang berisi tata cara wudhu dan shalat lima waktu (Ardiansyah \& Rahayu, 2016). Dan juga penelitian yang menghasilkan sebuah aplikasi prototipe dengan konsep multimedia, dengan konten berupa panduan sholat dan doa bagi anak-anak yang 
memiliki gangguan pendengaran. Hasil penelitian setelah melalui evaluasi, mampu memenuhi kebutuhan pengguna yakni sebesar 4,42 dari skala 5 (Robi'in \& Tyas, 2018).

Berdasarkan penelitian sebelumnya itulah menjadi latar belakang, dasar pemikiran juga acuan penelitian. Berbasis Android dapat diyakini akan stabil karena sejak dirilis telah dilakukan berbagai pembaruan berupa perbaikan bug dan penambahan fitur baru (Safaat, 2015). Tentu saja penelitian ini berbeda dari penelitian sebelumnya baik dari segi metode hingga domain nya yang mana peneliti menambahkan keperluan evaluasi dalam proses didik siswa, untuk selanjutnya dapat dimanfaatkan oleh pihak sekolah TK.

\section{Metode Penelitian}

\subsection{Metode}

Peneliti menggunakan metode penelitian dengan 5 (lima) tahap adalah tahap pengumpulan kebutuhan, tahap analisis kebutuhan, tahap desain aplikasi, tahap integrasi dan pengujian bentuk prototipe, tahap penerapan aplikasi prototipe dan tahap evaluasi. Tahapan penelitian dapat dilihat pada gambar 1

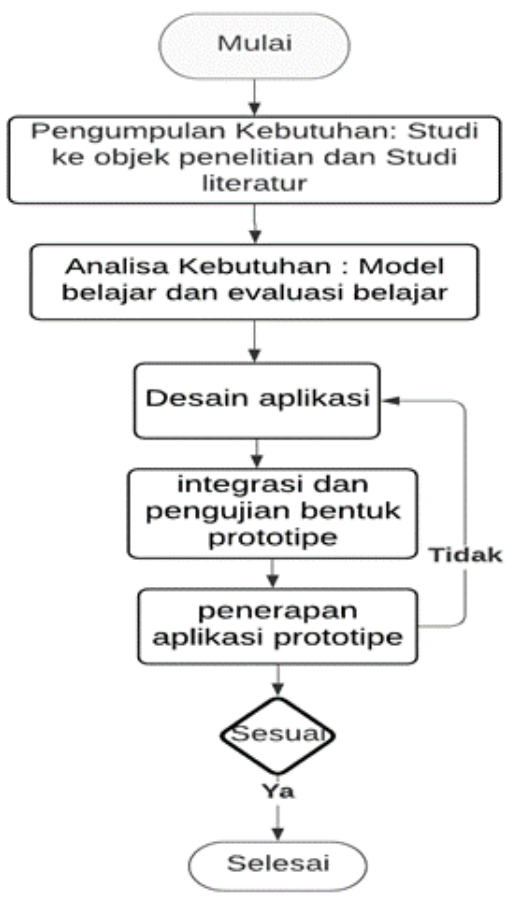

Gambar 1. Alur Metode yang akan digunakan

\subsection{Pengumpulan Kebutuhan}

Untuk tahap pengumpulan kebutuhan, peneliti melakukan 2 hal yakni observasi ke objek penelitian dan mempelajari literatur yang terkait. Pengumpulan kebutuhan ini untuk mengumpulkan data, informasi yang dibutuhkan untuk penelitian. Studi ke TK Alphabeta dengan melakukan observasi dan wawancara dengan guru TK, orang tua murid serta pemilik Yayasan TK Alpabeta.

Studi literatur mempelajari referensi pendukung penelitian, sehingga dapat memberikan input ke penelitian ini. Baik penelitian sebelumnya hingga teori sebagai dasar ilmu pengetahuan.

\subsection{Analisis Sistem}

Analisis sistem dilakukan melalu proses identifikasi dan evaluasi masalah yang ada, kesempatan untuk solusi, hambatan yang akan terjadi juga kebutuhan yang diharapkan agar kemudian mengusulkan perbaikan-perbaikannya (Jogiyanto, 2017). Sistem yang peneliti usulkan, digambarkan dalam Use Case terlihat pada gambar 2

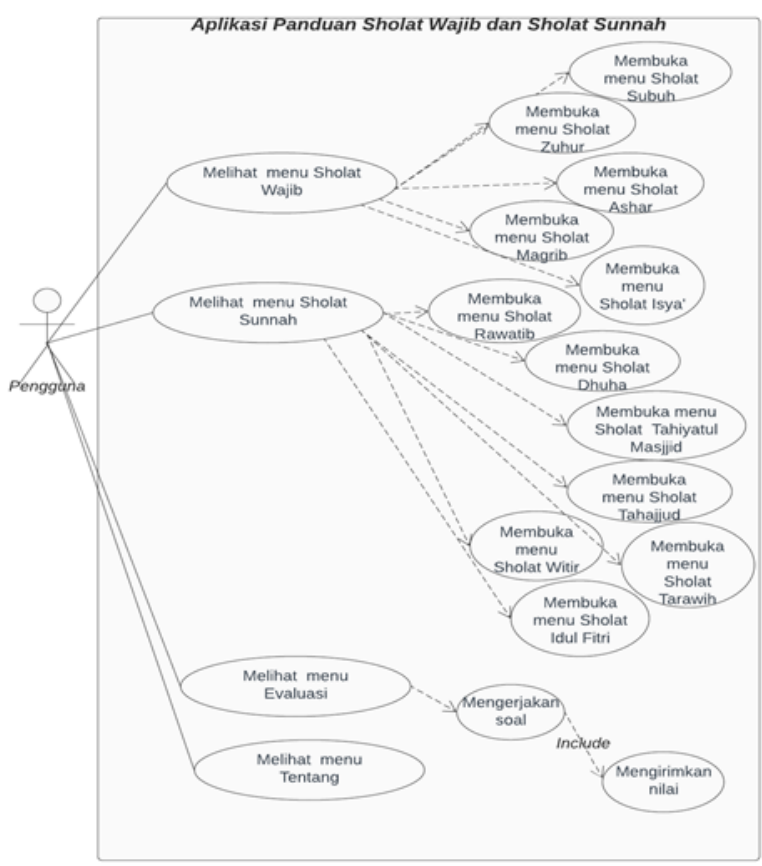

Gambar 2. Use Case Aplikasi Prototipe

Dalam use case dimaksud akan ada beberapa menu yang menjadi case penelitian ini, diantaranya sholat wajib, sholat sunnah, evaluasi, tentang. Di dalam setiap case ada penjabaran untuk masingmasing.

\subsection{Desain Aplikasi}

Dalam pembuatan aplikasi ini, merancang interface adalah bagian penting karena dengan merancang grafik dapat mempermudah dalam 
menganalisa apakah aplikasi yang dirancang sudah sesuai, sehingga tampilan interface dapat benarbenar mendukung tampilan aplikasi. Harapan untuk menghasilkan informasi yang berkualitas, menampilkan apakah sudah relevan antara design dengan yang akan diimplemntasikan, juga informasi lengkap berisi panduan sholat wajib dan sholat sunnah, akan dapat dicapai (Jogiyanto, 2017).

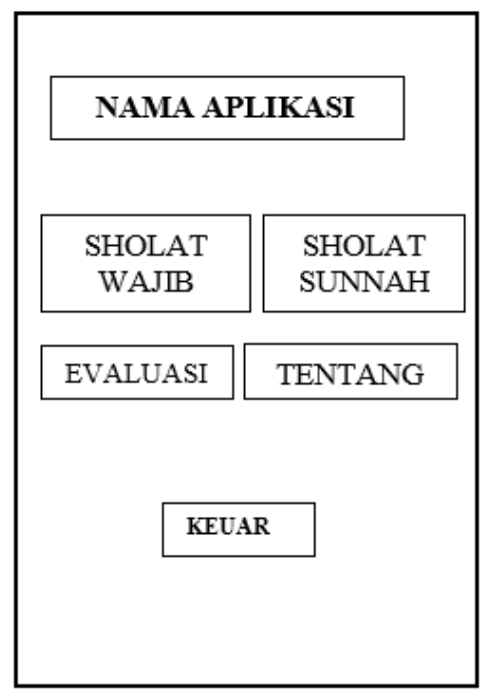

Gambar 3. Rancangan Menu Utama

Tampilan untuk rancangan menu utama, akan ada setiap case pada usecase, sehingga sesuai setiap konten yang tersedia.

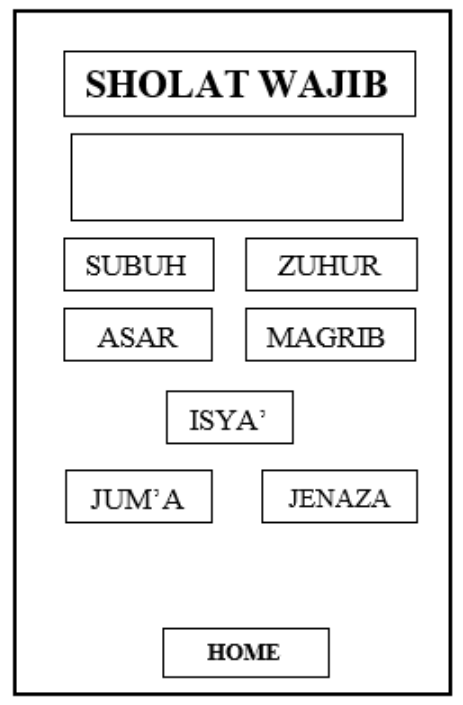

Gambar 4. Rancangan Menu Sholat Wajib

Tampilan yang akan digunakan saat menu sholat wajib dipilih oleh user atau pengguna.
Konten terdiri dengan Subuh, Zuhur, Asar, Magrib, Isya', Juma', Jenazah

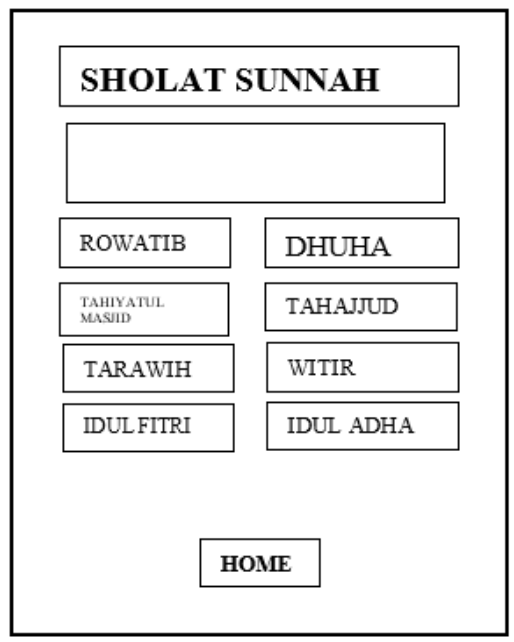

Gambar 5 Rancangan Menu Sholat Sunnah

Tampilan untuk menu sholat sunnah yang telah dipilih oleh pengguna, terdapat rowatib, dhuha, tahyatul masjid, tahajjud, tarawih, witir, idul fitri dan idul adha. Dengan juga tombol home pada sisi tengah sehingga memudahkan pengguna untuk kembali ke halaman awal

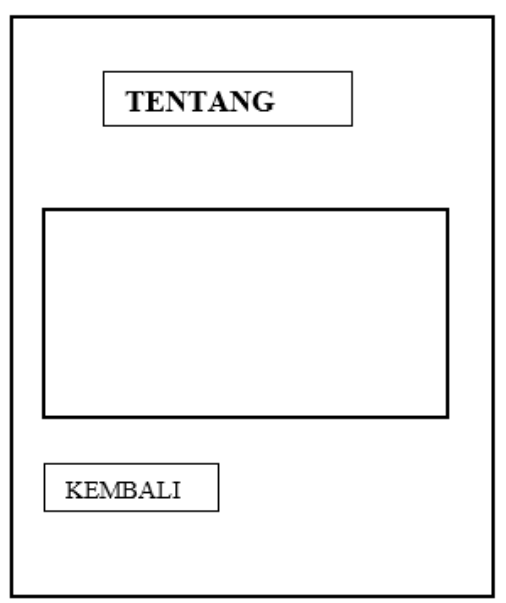

Gambar 6. Rancangan Menu Tentang

Menu Tentang akan menampilkan tentang pembuatan aplikasi. Menu Tentang ditunjukkan pada Gambar 6.

Gambar 7 adalah tampilan dari menu evaluasi untuk soal dengan pilihan jawaban kemudian setelah selesai evaluasi akan ditampilkan score menggunakan SMS Gateway dan muncul di aplikasi mobile. 

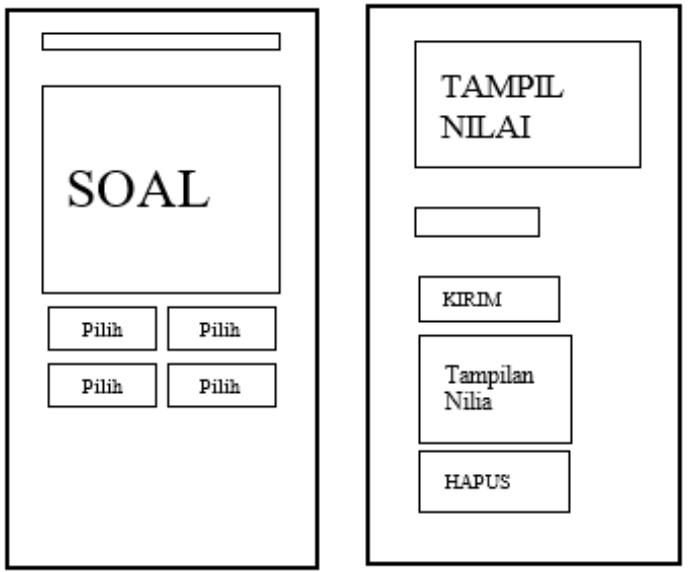

Gambar 7. Rancangan Menu Evaluasi

\section{Hasil Penelitian}

\subsection{Integrasi Bentuk Prototipe}

Integrasi bentuk prototipe merupakan tahap selanjutnya untuk lanjutan rancang bangun dari aplikasi panduan sholat ini, tahap ini sebagai tahap saat suatu sistem sudah siap untuk diterapkan dengan keadaan sebenarnya. Sehingga dapat diperoleh informasi apabila sistem yang dirancang bangun sudah dapat menghasilkan tujuan yang tepat guna untuk menyelesaikan masalah penelitian (Kadir,A.2017).

Berikut ini tabel untuk perangkat yang akan digunakan dalam integrasi prototipe.

Tabel 1. Rincian Kebutuhan Komputer

\begin{tabular}{|l|l|}
\hline Perangkat Keras & \multicolumn{2}{|c|}{ Spesifikasi } \\
\hline Processor & $\begin{array}{l}\text { Intel Core 2 Duo } \\
\text { E8400 @3.00GHz }\end{array}$ \\
\hline Hard Disk & 250GB \\
\hline Memory RAM & 4 GB \\
\hline Monitor & $\begin{array}{l}\text { 14" HD (LED) } \\
\text { Display }\end{array}$ \\
\hline Mouse & Standart \\
\hline Keyboard & Standart \\
\hline
\end{tabular}

Tabel 2. Rincian Kebutuhan Smartphone

\begin{tabular}{|l|l|}
\hline \multicolumn{1}{|c|}{ Perangkat Keras } & \multicolumn{1}{c|}{ Spesifikasi } \\
\hline Phone & Sony Xperia Z3 Compact \\
\hline Nomer Model & D5833 \\
& \\
\hline Versi kernel & 3.4.0-perf-gc14c2d5 \\
\hline Versi Android & Android 6.0.1 (Marshmallow) \\
\hline Memori RAM & 2 GB \\
\hline Processor & Quad-core 2.5 GHz Krait 400 \\
\hline & \\
\hline
\end{tabular}

Tabel 3. Rincian Perangkat Lunak (Software)

\begin{tabular}{|l|l|}
\hline \multicolumn{1}{|c|}{ Perangkat Lunak } & \multicolumn{1}{|c|}{ Spesifikasi } \\
\hline $\begin{array}{l}\text { Sistem Operasi } \\
\text { Komputer }\end{array}$ & Windows 7 Ultimate 64 Bit \\
\hline Web Browser & $\begin{array}{l}\text { UCBrowser_V7.0.69.1022_ } \\
4770\end{array}$ \\
\hline $\begin{array}{l}\text { Aplikasi } \\
\text { Perancangan }\end{array}$ & MIT App Inventor 2 \\
\hline $\begin{array}{l}\text { Bahasa } \\
\text { Pemrograman }\end{array}$ & Java, JDK 7.0_40 \\
\hline $\begin{array}{l}\text { Aplikasi } \\
\text { Permodelan }\end{array}$ & StarUML_V2.8.0 \\
\hline $\begin{array}{l}\text { Aplikasi Pengolah } \\
\text { Kata }\end{array}$ & Microsoft Office 2010 \\
\hline
\end{tabular}

Pada tahap ini antarmuka yang dibuat setelah tahap perancangan. Adapun bentuk utama hasil implementasi adalah tampilan menu utama, tampilan menu sholat, tampilan panduan, evaluasi dan tentang.

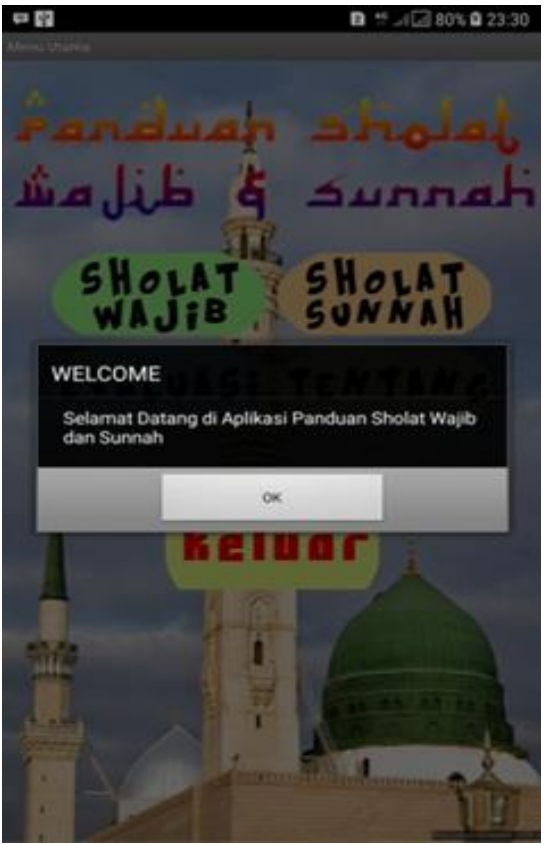

Gambar 8. tangkap layar Menu Utama 


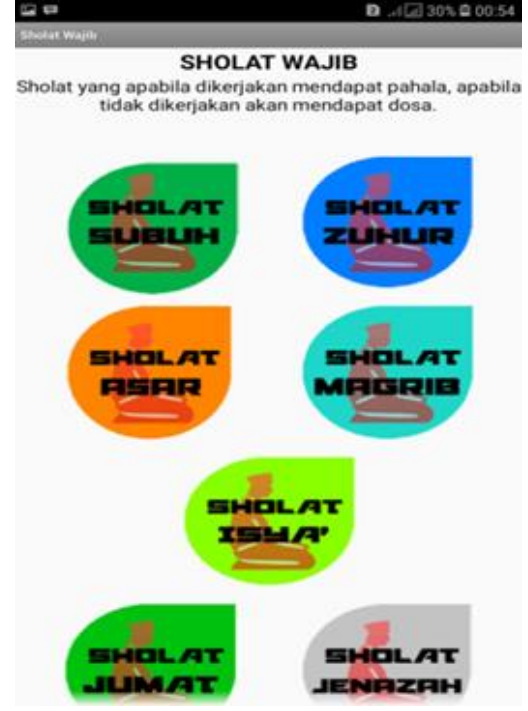

Gambar 9. Tangkap layar Sholat Wajib

Tangkap layar setelah pengguna masuk ke menu utama sholat wajib, dalam setiap isian dari sholat wajib akan menggunakan tulisan, gambar dan audio bacaan surah sehingga memudahkan murid mendengar saja tanpa perlu membaca bagian surah. Isian nya lengkap dari awal takbiratul ihram hingga tahiyyat akhir (Labib, 2016)

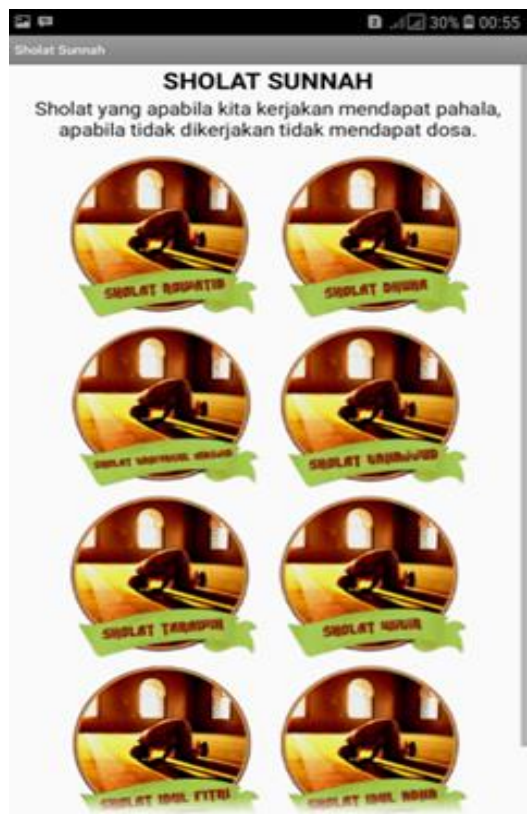

Gambar 10. Tangkap layar Menu Sholat Sunnah

Pada menu sholat sunnah menggunakan prinsip yang sama dengan sholat wajib, namun konten berbeda dengan isian sholat sunnah.
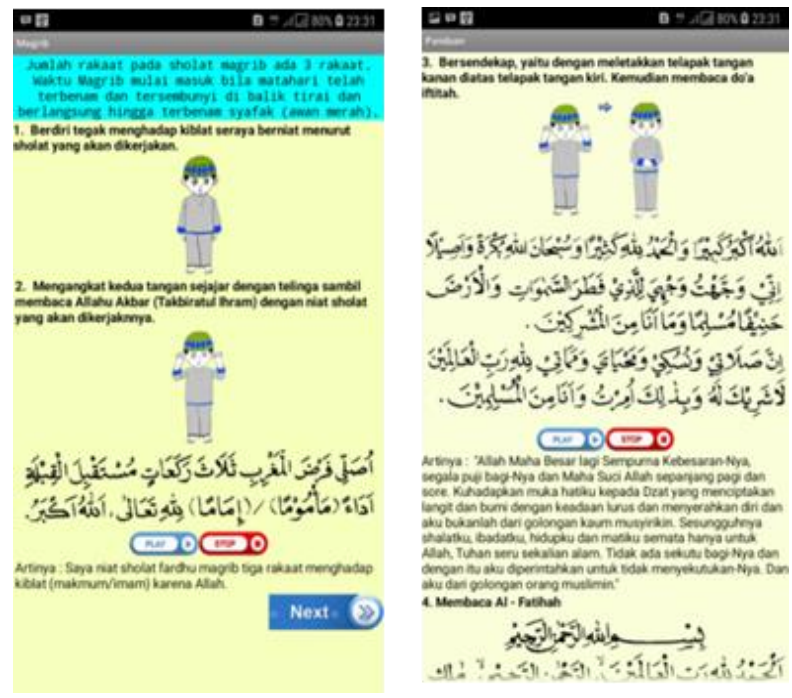

Gambar 11. Tangkap layar Menu Panduan Sholat

Tangkap layar ada tombol play dan stop untuk audio, serta tombol next untuk melanjutkan halaman.

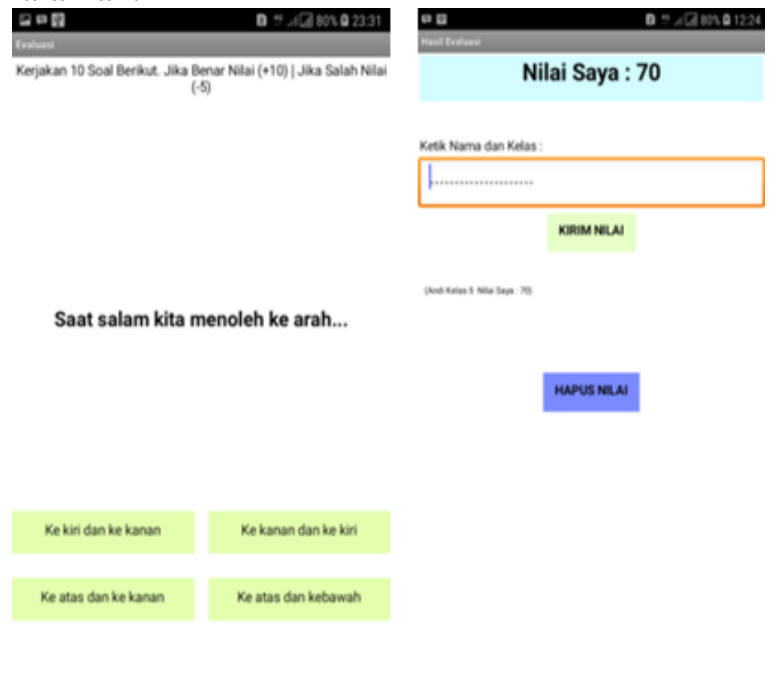

Gambar 12. Tangkap layar Menu Evaluasi

Pada menu evaluasi akan muncul soal dengan empat pilihan jawab sebanyak 10 soal kemudian setiap soal berbobot +10 jika jawaban benar dan -5 jika jawaban salah. Nilai yang sudah dapat dikirimkan menggunakan SMS gateway sehingga guru dapat mengirimkan langsung ke orang tua murid.

\section{Kesimpulan}

Bersumber pada hasil pengujian blackbox yang telah dilakukan, peneliti mencoba simpulkan bahwa aplikasi prototipe yang dibangun secara fungsional sesuai antara analisa, design prototipe 
dengan integrasi aplikasi prototipe, sesuai dengan yang diharapkan. Semua button pada aplikasi ini dapat berjalan dengan baik, tanpa kesalahan sesuai dengan rancangan. Evaluasi yang berdasarkan hasil pengisian form kuesioner dari 19 responden memberikan hasil yang sangat baik dengan presentasi hampir $99 \%$.

\section{$5 \quad$ Saran}

Peneliti mengharapkan penelitian ini dapat bermanfaat untuk selanjutnya dapat dikembangkan dan ditambahkan sehingga menjadi penelitian berkelanjutan. Berikut ini beberapa hal yang disarankan yang mungkin dapat digunakan sebagai awal pengembangan.

1. Diperlukan alat bantu yang berbeda dalam pembangunan aplikasi android selain menggunakan AppInventor untuk rancang bangun aplikasi panduan sholat, untuk pengembangan selanjutnya misal dengan teknologi hybrid agar mampu membangun aplikasi platform lainnya seperti iOS.

2. Diperlukan adanya perbaikan aplikasi dengan menambahkan fitur lain seperti :

a. Menambahkan animasi gerakan sholat, materi sholat yang lain, doa doa harian. Sehingga informasi yang tersedia lebih lengkap.

b. Membuat tambahan user admin untuk mengubah isian soal, memilih doa untuk surat pendek, dan sebagainya. Sehingga lebih fleksibel untuk digunakan user guru.

\section{Referensi}

Amrulloh, A. (2016). Pendidikan Habituasi Ibadah Anak: Menelusuri Validitas dan Menangkap Pesan Hadits Perintah Shalat Anak. Didaktika Religia, 4(1), 1-28.

Ardiansyah, R., \& Rahayu, S. (2016). Pengembangan Aplikasi Tata Cara Wudhu dan Sholat Untuk Anak menggunakan Sistem Multimedia. Jurnal
Algoritma Sekolah Tinggi Teknologi Garut.

Jogiyanto, H. M. (2017). Analisis dan Desain (Sistem Informasi Pendekatan Terstruktur Teori dan Praktek Aplikasi Bisnis). Yogyakarta: Andi.

Indonesia,R. 2003 Undang-Undang Sistem Pendidikan Nasional, Jakarta: Sekretariat Negara.

Kadir, A. (2017). Pengenalan sistem informasi edisi revisi. Yogyakarta: Andi.

Labib. (2016). Risalah Sholat Lengkap. Surabaya : Anugerah.

Lesmana, H. C., Isnanto, R., \& Widianto, E. D. (2016). Perancangan Aplikasi "SHOLAT YUKK" Pada Android Sebagai Media Pembelajaran Ibadah Shalat Anak-Anak. Jurnal Teknologi Dan Sistem Komputer, $\quad 4(4), \quad 502$. https://doi.org/10.14710/jtsiskom.4.4.2016.50209

Maharizki, M. F., Sanjaya, M. B., \& Hendriyanto, R. (2016). Aplikasi Tuntunan Shalat Lengkap Dan Doa-Doa Agama Islam Berbasis Android. Applied Science, 2(1), 211-219.

Muiz, A. U. (2013). Panduan Sholat Terlengkap. Jakarta: Pustaka Media

Mulyadi. (2013). Android App Inventor. Yogyakarta: Multimedia Centre Publishing.

Rahmatullah, M. A. A. (2016). Kitab Lengkap Sholat, Dzikir, Sholawat, dan Do'a Terpopuler Sepanjang Tahun. Yogyakarta : Sabil.

Marjuni, A., \& Harun, H. (2019). Penggunaan Multimedia Online Dalam Pembelajaran. Idaarah: Jurnal Manajemen Pendidikan, 3(2), 194-204.

Robi'in, B., \& Tyas, Z. A. (2018). Desain Aplikasi Mobile Panduan Sholat Dan Doa Untuk Anak Gangguan Pendengaran. ILKOM Jurnal Ilmiah, 10(3), 290-297. https://doi.org/10.33096/ilkom.v10i3.366.290297.

Safaat, N. (2012). Pemrograman aplikasi mobile smartphone dan tablet pc berbasis android. Bandung: informatika. 